\title{
Determination of lightning currents from far electromagnetic fields: Effect of a strike object
}

\author{
J.L. Bermudez ${ }^{\mathrm{a}, 1}$, F. Rachidi ${ }^{\text {b,* }}$,W. Janischewskyj ${ }^{\mathrm{c}}$, V. Shostak ${ }^{\mathrm{d}}$, M. Rubinstein ${ }^{\mathrm{a}}$, \\ D. Pavanello ${ }^{\text {, }}$ A.M. Hussein ${ }^{\mathrm{e}}$, J.S. Chang ${ }^{\mathrm{f}}$, M. Paolone ${ }^{\mathrm{g}}$ \\ aU niversity of A pplied Sciences of W estern Switzerland, Y verdon, Switzerland \\ ${ }^{b} S$ wiss F ederal Institute of T echnology, P ower Systems L aboratory, EPFL -LRE, 1015 L ausanne, Switzerland \\ 'U niversity of T oronto, D epartment of Electrical and Computer Engineering, T oronto, Canada \\ ${ }^{\mathrm{d} K}$ yiv Polytechnic Institute, Kiev, U kraine \\ ${ }^{e}$ R yerson U niversity, Electrical and Computer Engineering D epartment, Toronto, C anada \\ ${ }_{\mathrm{f}}^{\mathrm{M}} \mathrm{cM}$ aster U niversity, $\mathrm{H}$ amilton, Canada \\ gU niversity of Bologna, Bologna, I taly
}

Received 13 September 2004; accepted 13 September 2006

Available online 30 October 2006

\begin{abstract}
We discuss in this paper the influence of the presence of an elevated strike object on the peak of the lightning return stroke current determined from remote field measurements. We develop analytical expressions relating the lightning return stroke channel-base current and the far electromagnetic field for different specific cases, namely, (1) ground-initiated return strokes (classical transmission line (TL) model), (2) ground-initiated return strokes including possible reflections at ground level, (3) tall strike objects for which the current's zero-to-peak time is smaller than the travel time along the object, and (4) electrically short strike objects. It is shown that for tall structures, the field enhancement relative to a return stroke initiated at ground level is expressed through a factor equal to $\mathrm{k}_{\text {tall }}=\left[1+\mathrm{c} / \mathrm{v}\left(1-2 \rho_{\mathrm{t}}\right)\right] /\left(1-\rho_{\mathrm{t}}\right)$, where $\mathrm{v}$ and $\mathrm{c}$ are the return stroke front speed and the speed of light in vacuum, respectively, and $\rho_{\mathrm{t}}$ is the top reflection coefficient. For very short towers and/or very slow return stroke current wavefronts, when the condition $t_{f} \gg h / c$ applies, expressions relating the far electromagnetic field and the return stroke current were also derived. For case (2), return strokes initiated at ground level, the field enhancement relative to a return stroke initiated at ground level, case (1), is expressed through a factor equal to $\mathrm{k}_{\text {short }}=\left(1+(\mathrm{c} / \mathrm{v}) \rho_{\mathrm{ch}-\mathrm{g}}\right) /\left(1+\rho_{\mathrm{ch}-\mathrm{g}}\right)$, where $\rho_{\mathrm{ch}-\mathrm{g}}$ represents the reflection coefficient between the lightning channel and the grounding impedance.
\end{abstract}

(C) 2006 Elsevier B.V. All rights reserved.

Keywords: Lightning; Strike object; Tall towers; Return stroke models; Electromagnetic fields; Return stroke current

\section{Introduction}

The determination of the peak return stroke current from remotely measured electric or magnetic fields considerably facilitates the collection of lightning return stroke current data without having to instrument towers or trigger the lightning artificially, and without the inherent relative inefficiency associated with those methods. This is especially true nowadays because of the widespread use of

\footnotetext{
*Corresponding author.

E-mail address: farhad.rachidi@epfl.ch (F. Rachidi).

${ }^{1}$ Currently with ABB-Sécheron, Geneva, Switzerland.
}

lightning location systems. Indeed, such systems are already used also to provide estimates of lightning current parameters (e.g. [1-3]).

The theoretical estimation of return stroke currents from remote electromagnetic fields depends on the adopted return stroke model. Based on the transmission line (TL) model, for an observation point at ground level, the radiated (far) electric and magnetic field peaks produced by a vertical lightning channel terminated directly at ground are simply proportional to the channel base current peaks [4]

$$
E_{Z}^{f a r}(r, t+r / c)=-\frac{v}{2 \pi \varepsilon_{0} c^{2} r} i(0, t),
$$


$H_{\varphi}^{\mathrm{far}}(r, t+r / c)=\frac{v}{2 \pi c r} \mathrm{i}(0, \mathrm{t})$,

where $i(0, t)$ is the current at the channel-base, $v$ is the return stroke speed, and $r$ is the distance from the channel-base to the observation point. Eqs. (1) and (2) are derived assuming that the return stroke is initiated at ground.

Recently, experimental data on instrumented towers and theoretical investigations have shown that the above expressions are not applicable to lightning strikes to elevated objects [5-8]. The aim of this paper is to analyze the relation between lightning currents and distant electromagnetic fields for different specific cases, namely:

- ground-initiated return strokes: reference case corresponding to the classical return stroke models;

- strokes terminating on tall structures, where the current risetime, $t_{f}$, is smaller than $2 \mathrm{~h} / \mathrm{c}, \mathrm{h}$ being the height of the structure;

- strokes terminating on electrically short structures, where $t_{f} \gg h / c$, and, finally

- the special case of electrically short structures when $\mathrm{h}=0$, in other words ground-initiated strokes but taking into account possible reflections at ground level (channel-grounding impedance discontinuity).

For each case, we will derive expressions relating the peak value of the far field to the peak value of the channel base current. The analysis is based on the TL model. We will discuss, however, the generalization of the results to other engineering models.

\section{TL model for lightning return strokes extended to include an elevated strike object}

Several engineering return stroke models have been extended to account for the presence of a tall strike object in the expressions of the lightning return stroke current along the channel (e.g. [5,9-15]). In this paper, we will use the version of the TL return stroke model recently extended in [16] to include the effect of the elevated strike object.

Representing the elevated strike object of height $h$ as an ideal (lossless) transmission line of length $\mathrm{h}$ with constant current reflection coefficients $\rho_{\mathrm{t}}$ and $\rho_{\mathrm{g}}$ at its extremities, the expression for the spatial-temporal distribution of the current along the strike object and along the channel are given by $[16,17]$

$$
\begin{aligned}
\mathrm{i}(\mathrm{z}, \mathrm{t})= & \left(1-\rho_{\mathrm{t}}\right) \sum_{\mathrm{n}=0}^{\infty}\left[\rho_{\mathrm{t}}^{\mathrm{n}} \rho_{\mathrm{g}}^{\mathrm{n}} \mathrm{i}_{\mathrm{o}}\left(\mathrm{h}, \mathrm{t}-\frac{\mathrm{h}-\mathrm{z}}{\mathrm{c}}-\frac{2 \mathrm{nh}}{\mathrm{c}}\right)\right. \\
& \left.+\rho_{\mathrm{t}}^{\mathrm{n}} \rho_{\mathrm{g}}^{\mathrm{n}+1} \mathrm{i}_{\mathrm{o}}\left(\mathrm{h}, \mathrm{t}-\frac{\mathrm{h}+\mathrm{z}}{\mathrm{c}}-\frac{2 \mathrm{nh}}{\mathrm{c}}\right)\right], \quad 0 \leqslant \mathrm{z} \leqslant \mathrm{h},
\end{aligned}
$$

$$
\begin{aligned}
\mathrm{i}(\mathrm{z}, \mathrm{t})= & \mathrm{i}_{\mathrm{o}}\left(\mathrm{h}, \mathrm{t}-\frac{\mathrm{z}-\mathrm{h}}{\mathrm{v}}\right)-\rho_{\mathrm{t}} \mathrm{i}_{\mathrm{o}}\left(\mathrm{h}, \mathrm{t}-\frac{\mathrm{z}-\mathrm{h}}{\mathrm{c}}\right) \\
& +\left(1-\rho_{\mathrm{t}}\right)\left(1+\rho_{\mathrm{t}}\right) \sum_{\mathrm{n}=0}^{\infty} \rho_{\mathrm{g}}^{\mathrm{n}+1} \rho_{\mathrm{t}}^{\mathrm{n}} \\
& \times \mathrm{i}_{\mathrm{o}}\left(\mathrm{h}, \mathrm{t}-\frac{\mathrm{h}+\mathrm{z}}{\mathrm{c}}-\frac{2 \mathrm{nh}}{\mathrm{c}}\right), \quad \mathrm{h}<\mathrm{z}<\mathrm{H}_{\mathrm{T}},
\end{aligned}
$$

where the 'undisturbed' current $i_{o}(h, t)$ is the idealized current that would be measured at the tower top if the current reflection coefficients at both its extremities were equal to zero. Note that Eqs. (1) and (2) can be equivalently expressed in terms of the short-circuit current $\mathrm{i}_{\mathrm{sc}}(\mathrm{t})=2 \mathrm{i}_{\mathrm{o}}(\mathrm{h}, \mathrm{t})[20]$.

$\mathrm{H}_{\mathrm{T}}$ represents the total height of both the lightning channel and the elevated strike object.

We will disregard any upward connecting leader and any reflections at the return stroke wavefront, even though it has been shown in [15] that some features of the radiated field could be attributed to these phenomena.

The bottom reflection coefficient for the current in the tower can be expressed in terms of the characteristic impedance of the tower $Z_{t}$ and the grounding system impedance $Z_{g}$,

$\rho_{\mathrm{g}}=\frac{\mathrm{Z}_{\mathrm{t}}-\mathrm{Z}_{\mathrm{g}}}{\mathrm{Z}_{\mathrm{t}}+\mathrm{Z}_{\mathrm{g}}}$

The top reflection coefficient for the current in the tower can be expressed in terms of the characteristic impedance of the tower $Z_{t}$ and the equivalent impedance of the lightning return-stroke channel $Z_{\mathrm{ch}}$,

$\rho_{\mathrm{t}}=\frac{\mathrm{Z}_{\mathrm{t}}-\mathrm{Z}_{\mathrm{ch}}}{\mathrm{Z}_{\mathrm{t}}+\mathrm{Z}_{\mathrm{ch}}}$.

This top reflection coefficient can be defined in a similar manner for currents observed in the channel and, in that case, $Z_{t}$ and $Z_{\text {ch }}$ should be interchanged in (5).

\section{Radiated electromagnetic field}

The general expressions for the vertical electric field and the azimuthal magnetic field from a vertical antenna above a perfectly conducting ground, for an observation point at ground level (see Fig. 2), are given by [18]

$$
\begin{aligned}
E_{z}(r, t)= & \frac{1}{2 \pi \varepsilon_{0}}\left[\int_{0}^{H} \frac{2 z^{2}-r^{2}}{R^{5}} \int_{R / c}^{t} i(z, \tau-R / c) d \tau d z\right. \\
& +\int_{0}^{H} \frac{2 z^{2}-r^{2}}{c R^{4}} i(z, t-R / c) d z \\
& \left.-\int_{0}^{H} \frac{r^{2}}{c^{2} R^{3}} \frac{\partial i(z, t-R / c)}{\partial t} d z\right], \\
H_{\varphi}(r, t)= & \frac{1}{2 \pi}\left[\int_{0}^{H} \frac{r}{R^{3}} i(z, t-R / c) d z\right. \\
& \left.+\int_{0}^{H} \frac{r}{c R^{2}} \frac{\partial i(z, t-R / c)}{\partial t} d z\right]
\end{aligned}
$$


where $\mathrm{H}$ is the height of the return stroke wavefront as seen by the observer, $r$ is the horizontal distance between the channel and the observation point, and $R$ is the distance between a single dipole located at a height $\mathrm{Z}$ above ground and the observation point $\left(R=\sqrt{r^{2}+z^{2}}\right)$.

Let us consider here only the radiated electric field. For distant observation points, neglecting the static and induction components of the electric field, and considering $R \cong r$ and $r \gg H$, the general expression for the electric field [18] for an observation point located at ground level reduces to

$E_{z}(r, t) \cong-\frac{1}{2 \pi \varepsilon_{0} c^{2} r} \int_{0}^{H} \frac{\partial i\left(z^{\prime}, t-r / c\right)}{\partial t} d z^{\prime}$.

Introducing the expressions for the spatial-temporal distribution of the current in (3a) and (3b) into (8), and after appropriate mathematical manipulations, we obtain expression (9) for the radiated (far) electric field $[17,19]$

$$
\begin{aligned}
\mathrm{E}_{\mathrm{z}}(\mathrm{r}, \mathrm{t}+\mathrm{r} / \mathrm{c})= & -\frac{\mathrm{v}}{2 \pi \varepsilon_{\mathrm{o}} \mathrm{c}^{2} \mathrm{r}}\left[1+\frac{\mathrm{c}}{\mathrm{v}}\left(1-2 \rho_{\mathrm{t}}\right)\right] \mathrm{i}_{\mathrm{o}}(\mathrm{h}, \mathrm{t}) \\
& -\frac{\left(1-\rho_{\mathrm{t}}\right)}{2 \pi \varepsilon_{\mathrm{o}} \mathrm{cr}} \sum_{\mathrm{n}=0}^{\infty}\left\{\left(\rho_{\mathrm{g}}-1\right) \rho_{\mathrm{g}}^{\mathrm{n}} \rho_{\mathrm{t}}^{\mathrm{n}}\right. \\
& \times \mathrm{i}_{\mathrm{o}}\left(\mathrm{h}, \mathrm{t}-\frac{(2 \mathrm{n}+1) \mathrm{h}}{\mathrm{c}}\right)+2 \rho_{\mathrm{g}}^{\mathrm{n}+1} \rho_{\mathrm{t}}^{\mathrm{n}+1} \\
& \left.\times \mathrm{i}_{\mathrm{o}}\left(\mathrm{h}, \mathrm{t}-\frac{2(\mathrm{n}+1) \mathrm{h}}{\mathrm{c}}\right)\right\} .
\end{aligned}
$$

Similarly, for the magnetic field,

$$
\begin{aligned}
\mathrm{H}_{\varphi}(\mathrm{r}, \mathrm{t}+\mathrm{r} / \mathrm{c})= & \frac{\mathrm{v}}{2 \pi \mathrm{cr}}\left[1+\frac{\mathrm{c}}{\mathrm{V}}\left(1-2 \rho_{\mathrm{t}}\right)\right] \mathrm{i}_{\mathrm{o}}(\mathrm{h}, \mathrm{t}) \\
& +\frac{\left(1-\rho_{\mathrm{t}}\right)}{2 \pi \mathrm{r}} \sum_{\mathrm{n}=0}^{\infty}\left\{\left(\rho_{\mathrm{g}}-1\right) \rho_{\mathrm{g}}^{\mathrm{n}} \rho_{\mathrm{t}}^{\mathrm{n}}\right. \\
& \times \mathrm{i}_{\mathrm{o}}\left(\mathrm{h}, \mathrm{t}-\frac{(2 \mathrm{n}+1) \mathrm{h}}{\mathrm{c}}\right)+2 \rho_{\mathrm{g}}^{\mathrm{n}+1} \rho_{\mathrm{t}}^{\mathrm{n}+1} \\
& \left.\times \mathrm{i}_{\mathrm{o}}\left(\mathrm{h}, \mathrm{t}-\frac{2(\mathrm{n}+1) \mathrm{h}}{\mathrm{c}}\right)\right\} .
\end{aligned}
$$

Eqs. (9) and (10) represent the general expressions for the far radiated electric and magnetic fields in the presence of an elevated strike object, under the assumptions introduced in $[17,19]$.

\section{Relations between return stroke far fields and currents}

\subsection{Ground-initiated return strokes}

This case corresponds to the classical TL model. Eqs. (1) and (2) can be rewritten in terms of current and field peak values:

$E_{z \text { peak }}^{\text {far }}=-\frac{V}{2 \pi \varepsilon_{0} c^{2} r} I_{\text {peak }}$
$\mathrm{H}_{\varphi \text { peak }}^{\mathrm{far}}=\frac{\mathrm{V}}{2 \pi \mathrm{cr}} \mathrm{I}$ peak.

\subsection{Tower-initiated return stroke}

Let us call $t_{\mathrm{f}}$ the zero-to-peak risetime of the lightning return stroke current waveform. We will consider two cases: (1) 'tall' structures, for which the round-trip propagation time from top to bottom within the tower $(2 h / c)$ is greater than the time $t_{f}$, in which case the current transmitted into the tower reaches its peak before the arrival of any ground reflections (none of the reflections overlap with it); and, (2) electrically short structures, for which the round-trip propagation time is much shorter than the lightning return stroke current wavefront $t_{f}$; in which case we can neglect propagation delays along the tower.

\subsection{1. 'Tall' strike object $\left(t_{f}<2 h / c\right)$}

Noting that all terms on the right-hand side of Eqs. (9) and (10) except for the first are zero for times satisfying the inequality $\left(t_{f}<2 h / c\right)$, we can write for $t=t_{f}$,

$$
\begin{aligned}
& E_{z}^{f a r}\left(r, t_{f}+r / c\right)=-\frac{v}{2 \pi \varepsilon_{o} c^{2} r}\left[1+\frac{c}{v}\left(1-2 \rho_{t}\right)\right] i_{o}\left(h, t_{f}\right), \\
& H_{\varphi}^{f a r}\left(r, t_{f}+r / c\right)=\frac{v}{2 \pi c r}\left[1+\frac{c}{v}\left(1-2 \rho_{t}\right)\right] i_{o}\left(h, t_{f}\right) .
\end{aligned}
$$

Since the current on the right-hand side of Eqs. (13) and (14) is the first peak of the undisturbed current, and the fields on the left-hand side are the first peak in the far electric and magnetic fields, we can write

$$
\begin{aligned}
& \mathrm{E}_{\mathrm{z} \text { peak }}=-\frac{\mathrm{V}}{2 \pi \varepsilon_{\mathrm{o}} \mathrm{C}^{2} \mathrm{r}}\left[1+\frac{\mathrm{C}}{\mathrm{V}}\left(1-2 \rho_{\mathrm{t}}\right)\right] \mathrm{I}_{\mathrm{o} \text { peak }}, \\
& \mathrm{H}_{\varphi \text { peak }}=\frac{\mathrm{V}}{2 \pi \mathrm{Cr}}\left[1+\frac{\mathrm{C}}{\mathrm{V}}\left(1-2 \rho_{\mathrm{t}}\right)\right] \mathrm{I}_{\text {o peak }},
\end{aligned}
$$

where $I_{o}$ peak is the first peak of the undisturbed current $\mathrm{i}_{\mathrm{o}}(\mathrm{h}, \mathrm{t})$.

It is important to note that the undisturbed current $\mathrm{i}_{\mathrm{o}}(\mathrm{h}, \mathrm{t})$ is different from the actual current pulse injected from the channel into the tower top. It would be therefore, more appropriate to express the electromagnetic field peaks as a function of the current transmitted into the tower, for which experimental data are usually available. To do that, one needs to express the undisturbed current peak $I_{\text {o peak }}$ as a function of the peak of the current transmitted into the tower, $I_{\text {peak }}$. Under the current conditions of tall towers $\left(t_{\mathrm{f}}<\mathrm{h} / \mathrm{c}\right)$, these two quantities are simply related by

$\mathrm{I}_{\text {peak }}=\left(1-\rho_{\mathrm{t}}\right) \mathrm{I}_{\mathrm{o} \text { peak }}$,

where $\rho_{\mathrm{t}}$ is given by (5).

Introducing (17) into (15) and (16), we obtain

$$
\begin{aligned}
& \mathrm{E}_{\mathrm{z} \text { peak }}=-\frac{\mathrm{v}}{2 \pi \varepsilon_{\mathrm{o}} \mathrm{c}^{2} \mathrm{r}} \mathrm{k}_{\text {tall }} \mathrm{l}_{\text {peak }}, \\
& \mathrm{H}_{\varphi \text { peak }}=\frac{\mathrm{v}}{2 \pi \mathrm{cr}} \mathrm{k}_{\text {tall }} \mathrm{l}_{\text {peak }},
\end{aligned}
$$


where $k_{\text {tall }}$ is given by

$\mathrm{k}_{\mathrm{tall}}=\frac{1+\left(1-2 \rho_{\mathrm{t}}\right) \mathrm{c} / \mathrm{v}}{1-\rho_{\mathrm{t}}}$.

Comparing Eqs. (18) and (19) with Eqs. (11) and (12), we can see that the enhancement effect of the tower can be quantified through the factor $\mathrm{k}_{\text {tall }}$.

Because of the condition $t_{f}<2 h / c$ imposed on the current, Eqs. (18) and (19) are independent of the structure's height $h$ and of the ground reflection coefficient $\rho_{\mathrm{g}}$.

It is also important to note that, as the grounding impedance of the tower is generally noticeably smaller than its own characteristic impedance and since the characteristic impedance is, in turn, appreciably lower than the equivalent impedance of the lightning channel (e.g. [20,21]), the current reflection coefficient at the ground $\rho_{\mathrm{g}}$ is positive and the top reflection coefficient $\rho_{\mathrm{t}}$ is negative. Thus, the factor $k_{\text {tall }}$ in Eqs. (19) and (20) is greater than 1, implying that the presence of the strike object enhances the electric and magnetic field peaks in comparison to return strokes initiated at ground level (Section 4.1).

Fig. 1 presents the variation of the enhancement factor $\mathrm{k}_{\text {tall }}$ as a function of the top reflection coefficient and the return stroke speed.

\subsubsection{Electrically short strike object $\left(t_{f} \gg 2 h / c\right)$}

Let us now consider the special case in which the strike object is electrically short. This would be the case, for instance, when lightning is initiated artificially from short platforms, or for very long-front pulses. This condition can be expressed mathematically by, $t_{f} \gg 2 h / c$.

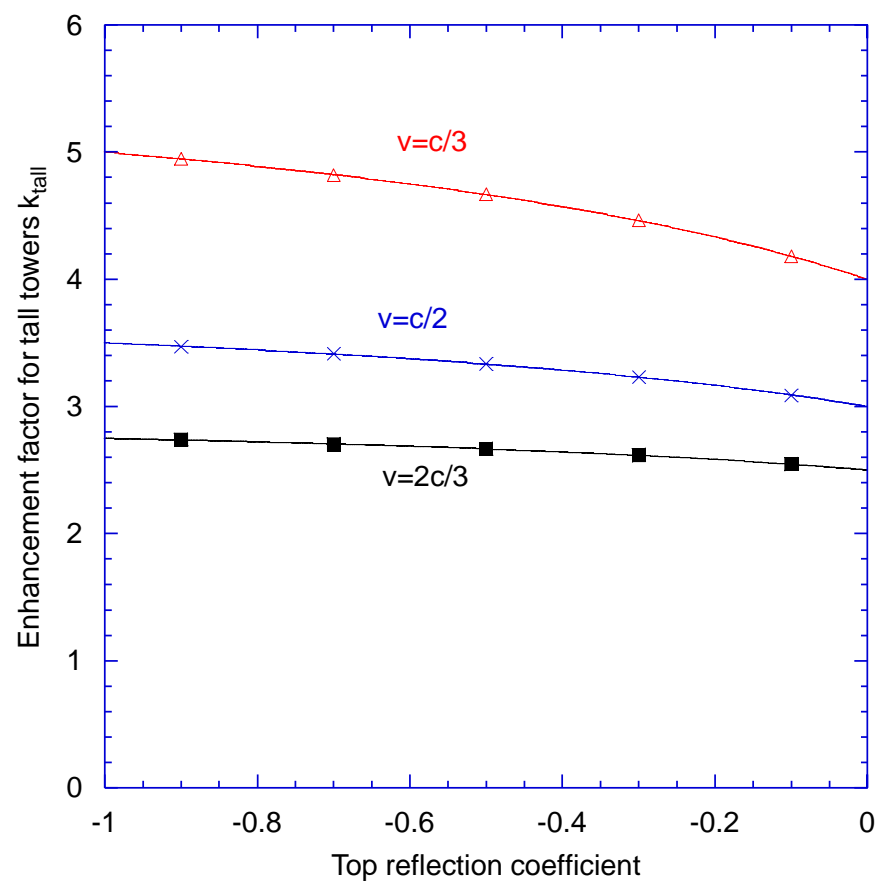

Fig. 1. Variation of the enhancement factor for a tall tower as a function of the top reflection coefficient $\rho_{\mathrm{t}}$ and the return stroke speed $\mathrm{v}$.
In this case, propagation along the tower can be neglected and closed-form expressions can be derived for the spatial-temporal distribution of the current along the strike object and along the channel.

Neglecting propagation phenomena along the tower (note that propagation effects in the channel still need to be taken into account), after straightforward mathematical manipulations [19], the expressions for the far electric and magnetic fields are given by

$$
\begin{aligned}
E_{z}^{f a r}\left(r, t+\frac{r}{c}\right) \cong & -\frac{v}{2 \pi \varepsilon_{0} c^{2} r}\left(1+\frac{c}{v} \rho_{c h-g}\right) i_{o}(h, t) \\
& -\frac{\left(1+\rho_{c h-g}\right) h}{2 \pi \varepsilon_{o} c^{2} r} \frac{\partial i_{o}(h, t)}{\partial t}, \\
H_{\varphi}^{f a r}\left(r, t+\frac{r}{c}\right) \cong & \frac{v}{2 \pi c r}\left(1+\frac{c}{v} \rho_{c h-g}\right) i_{o}(h, t) \\
& +\frac{\left(1+\rho_{c h-g}\right) h}{2 \pi c r} \frac{\partial i_{o}(h, t)}{\partial t},
\end{aligned}
$$

where $\rho_{\text {ch }-\mathrm{g}}=\left(\rho_{\mathrm{g}}-\rho_{\mathrm{t}}\right) /\left(1-\rho_{\mathrm{g}} \rho_{\mathrm{t}}\right)$.

It is interesting to note that after insertion of the expressions for $\rho_{\mathrm{g}}$ and $\rho_{\mathrm{t}}$ in terms of impedances, $\left(\rho_{\mathrm{g}}=\left(\mathrm{Z}_{\mathrm{t}}-\mathrm{Z}_{\mathrm{g}}\right) /\left(\mathrm{Z}_{\mathrm{t}}+\mathrm{Z}_{\mathrm{g}}\right) \quad\right.$ and $\quad \rho_{\mathrm{t}}=\left(\mathrm{Z}_{\mathrm{t}}-\mathrm{Z}_{\mathrm{ch}}\right) /\left(\mathrm{Z}_{\mathrm{t}}+\right.$ $\left.\left.Z_{\text {ch }}\right)\right), \quad \rho_{\text {ch }-\mathrm{g}}$ reduces to $\rho_{\text {ch }-\mathrm{g}}=\left(Z_{\mathrm{ch}}-Z_{\mathrm{g}}\right) /\left(Z_{\mathrm{ch}}+Z_{\mathrm{g}}\right)$, which is the reflection coefficient at ground level, and it is independent of the impedance of the electrically short tower.

As in the case of tall towers, we can express the undisturbed current $\mathrm{i}_{\mathrm{o}}(\mathrm{h}, \mathrm{t})$ in Eqs. (21) and (22) in terms of the current that would be measured at the top of the tower, $\mathrm{i}(\mathrm{h}, \mathrm{t})$, for which experimental data are usually available. These two currents can be related through [19]

$\mathrm{i}(\mathrm{h}, \mathrm{t})=\left(1+\rho_{\text {ch-g }}\right) \mathrm{i}_{\mathrm{o}}(\mathrm{h}, \mathrm{t})$.

Inserting Eq. (23) into Eqs. (21) and (22) yields

$$
\begin{aligned}
E_{z}^{f a r}\left(r, t+\frac{r}{c}\right) \cong & -\frac{v}{2 \pi \varepsilon_{0} c^{2} r} \frac{1+(c / v) \rho_{c h-g}}{1+\rho_{c h-g}} i(h, t) \\
& -\frac{h}{2 \pi \varepsilon_{0} c^{2} r} \frac{\partial i(h, t)}{\partial t}, \\
H_{\varphi}^{f a r}\left(r, t+\frac{r}{c}\right) \cong & \frac{v}{2 \pi c r} \frac{1+(c / v) \rho_{c h-g}}{1+\rho_{c h}-g}(h, t) \\
& +\frac{h}{2 \pi c r} \frac{\partial i(h, t)}{\partial t} .
\end{aligned}
$$

The far electric and magnetic fields associated with lightning strikes to electrically short structures include two terms. The first one, which is proportional to the undisturbed current, represents the contribution of the channel, while, the second one, which depends on the current derivative, represents the contribution of the strike object. 
4.3. Ground-initiated return strokes including reflections at ground level

Note that setting $h=0$ in (24) and (25) we can obtain a generalized form of Eqs. (1) and (2) for return strokes initiated at ground level, in which the reflections at ground level are taken into account,

$\mathrm{E}_{\mathrm{z}}^{\mathrm{far}}\left(\mathrm{r}, \mathrm{t}+\frac{\mathrm{r}}{\mathrm{c}}\right) \cong-\frac{\mathrm{v}}{2 \pi \varepsilon_{0} \mathrm{c}^{2} r} \frac{1+(\mathrm{c} / \mathrm{v}) \rho_{\mathrm{ch}-\mathrm{g}}}{1+\rho_{\text {ch }-\mathrm{g}}} \mathrm{i}(0, \mathrm{t})$

$\mathrm{H}_{\varphi}^{\mathrm{far}}\left(\mathrm{r}, \mathrm{t}+\frac{\mathrm{r}}{\mathrm{c}}\right) \cong \frac{\mathrm{v}}{2 \pi \mathrm{cr}} \frac{1+(\mathrm{c} / \mathrm{v}) \rho_{\mathrm{ch}-\mathrm{g}}}{1+\rho_{\mathrm{ch}-\mathrm{g}}} \mathrm{i}(0, \mathrm{t})$.

In terms of the peak amplitudes of the current and the fields (for $t=t_{f}$ ), (26) and (27) read

$\mathrm{E}_{\mathrm{z} \text { peak }}=-\frac{\mathrm{V}}{2 \pi \varepsilon_{0} \mathrm{C}^{2} \mathrm{r}} \mathrm{kl}$ peak,

$\mathrm{H}_{\varphi \text { peak }}=\frac{\mathrm{V}}{2 \pi \mathrm{Cr}} \mathrm{kl} \mathrm{peak}_{\text {pe }}$,

where $\mathrm{k}$ is given by

$\mathrm{k}=\frac{1+(\mathrm{c} / \mathrm{v}) \rho_{\mathrm{ch}-\mathrm{g}}}{1+\rho_{\mathrm{ch}-\mathrm{g}}}$

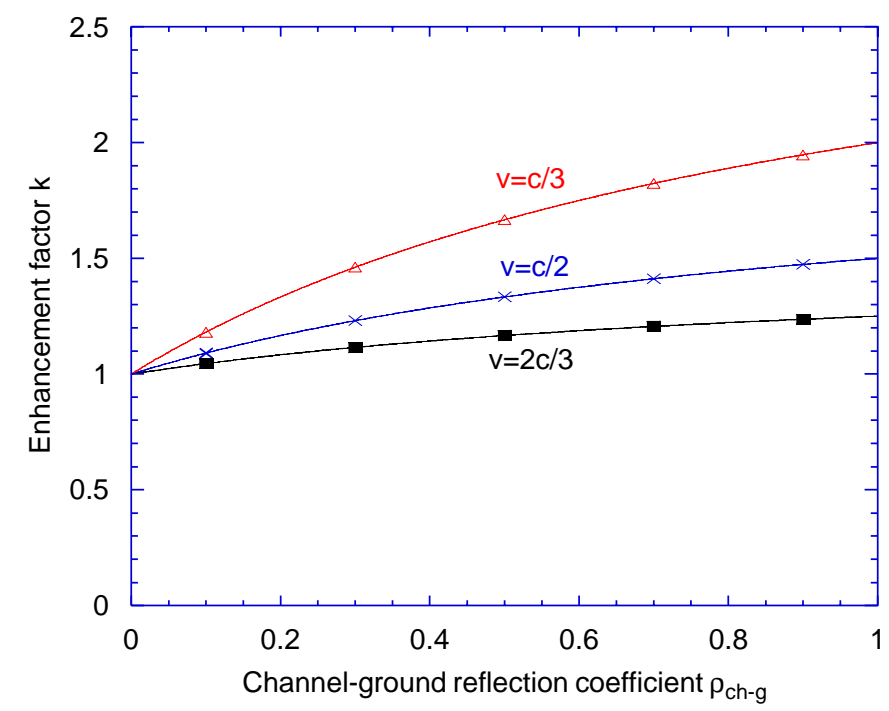

Fig. 2. Variation of the enhancement factor $k$ as a function of the reflection coefficient $\rho_{\text {ch-g }}$ and the return stroke speed $v$.
In terms of impedances, (30) can be written as

$\mathrm{k}=\frac{\mathrm{Z}_{\mathrm{ch}}(1+(\mathrm{c} / \mathrm{v}))+\mathrm{Z}_{\mathrm{g}}(1-(\mathrm{c} / \mathrm{v}))}{2 \mathrm{Z}_{\mathrm{ch}}}$.

Eqs. (28) and (29) will reduce to (11) and (12), respectively, when the reflection coefficient $\rho_{\text {ch-g }}$ equals 0 or, equivalently, when $Z_{\mathrm{ch}}=\mathrm{Z}_{\mathrm{g}}$. This consideration, that $\rho_{\text {ch-g }}$ equals 0 , implies that no current reflections will occur between the lightning channel and the ground, as assumed implicitly in the classical TL model. Thus, (28) and (29) can be considered as extended forms of (11) and (12) for return strokes initiated at ground level, in which the reflections at ground are incorporated in the TL model.

Eqs. (28) and (29) can be employed to find the return stroke electric and magnetic field peak amplitudes associated with lightning impacting the ground. These equations take into account the impedance discontinuity between the lightning channel and the grounding impedance. Comparing Eqs. (28) and (29) with Eqs. (11) and (12), we can see that including the grounding condition will result in an enhancement of far fields, which is quantified through the factor $k$. This enhancement factor $k$ is generally much smaller than the factor associated with tall towers $\mathrm{k}_{\text {tall }}$. Indeed, considering the ideal case when the grounding impedance is 0 and the return stroke speed $\mathrm{V}=\mathrm{c} / 2$, the enhancement factor $\mathrm{k}$ is equal to 1.5 (for the same speed $k_{\text {tall }}>3$, see Fig. 1).

Fig. 2 presents the variation of the enhancement factor $k$ as a function of $\rho_{\mathrm{ch}-\mathrm{g}}$ and the return stroke speed.

Table 1 summarizes the expressions relating the far field and the current for the different considered cases.

\section{Comparison}

Fig. 3 presents the results of comparison between the various expressions in Table 1. Note that, for the case of an electrically short structure, the peak value of the far field depends not only on the peak value of the current, but also on its derivative. However, in a first approach for the calculation of the field peak, the term involving the current derivative can be neglected and the case of electrically short towers becomes similar to the case of a ground-initiated return stroke, considering the reflection at ground level. The calculations in Fig. 3 are obtained considering $\rho_{\mathrm{t}}=-0.37, \rho_{\text {ch-g }}=0.66$, and $\mathrm{v}=1.2 \times 10^{8} \mathrm{~m} / \mathrm{s}$. A similar figure can be obtained for the magnetic field using the far-

Table 1

Summary of far electric field-current relationships for TL model for different considered cases

\begin{tabular}{ll}
\hline Case & Far field-current relation \\
\hline Ground initiated (classical TL model) & $E_{z}^{\operatorname{far}}(r, t+r / c)=-\frac{v}{2 \pi \varepsilon_{0} c^{2} \mathrm{r}} \mathrm{i}(0, \mathrm{t})$ \\
Tall towers, $\mathrm{t}_{\mathrm{f}}<2 \mathrm{~h} / \mathrm{c}$ & $\mathrm{E}_{z}^{\mathrm{far}}(\mathrm{r}, \mathrm{t}+\mathrm{r} / \mathrm{c})=-\frac{\mathrm{v}}{2 \pi \varepsilon_{0} \mathrm{c}^{2} \mathrm{r}} \frac{1+\left(1-2 \rho_{\mathrm{f}}\right) \mathrm{c} / \mathrm{v}}{1-\rho_{\mathrm{t}}} \mathrm{i}(\mathrm{h}, \mathrm{t})$ \\
Electrically short structures, $\mathrm{t}_{\mathrm{f}} \gg \mathrm{h} / \mathrm{c}$ & $\mathrm{E}_{z}^{\mathrm{far}}\left(\mathrm{r}, \mathrm{t}+\frac{\mathrm{r}}{\mathrm{c}}\right) \cong-\frac{\mathrm{v}}{2 \pi \varepsilon_{0} \mathrm{c}^{2} \mathrm{r}} \frac{1+(\mathrm{c} / \mathrm{v}) \rho_{\mathrm{ch}-\mathrm{g}}}{1+\rho_{\mathrm{ch}-\mathrm{g}}} \mathrm{i}(0, \mathrm{t})-\frac{\mathrm{h}}{2 \pi \varepsilon_{0} \mathrm{c}^{2} \mathrm{r}} \frac{\partial \mathrm{i}(0, \mathrm{t})}{\partial \mathrm{t}}$ \\
Ground initiated, taking into account reflection coefficient at ground & $\mathrm{E}_{z}^{\mathrm{far}}\left(\mathrm{Y}, \mathrm{t}+\frac{\mathrm{Y}}{\mathrm{c}}\right) \cong-\frac{\mathrm{v}}{2 \pi \varepsilon_{0} \mathrm{c}^{2} \mathrm{r}} \frac{1+(\mathrm{c} / \mathrm{v}) \rho_{\mathrm{ch}-\mathrm{g}}}{1+\rho_{\mathrm{ch}-\mathrm{g}}} \mathrm{i}(0, \mathrm{t})$ \\
\hline
\end{tabular}




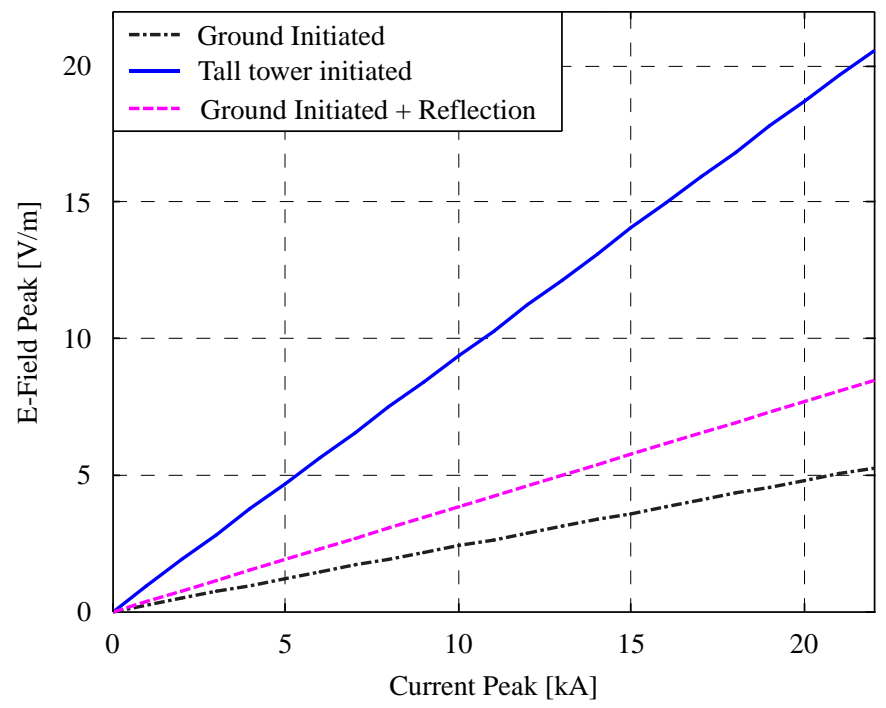

Fig. 3. Electric field peaks as a function of return stroke current peak, calculated at $100 \mathrm{~km}$. Other parameters, $\rho_{\mathrm{t}}=-0.37, \rho_{\text {ch-g }}=0.66$, $\mathrm{v}=1.2 \times 10^{8} \mathrm{~m} / \mathrm{s}$.

field relationship for an electromagnetic wave propagating in free space $\left(E / H=Z_{o}\right)$.

It can be seen that the presence of a tall tower enhances considerably the radiated fields. Also, possible reflections at ground level would increase, but to a lesser degree, the radiated fields.

\section{Conclusions}

The derived expressions show that, for tall structures satisfying the condition $t_{f}<2 h / c$, the field enhancement relative to a return stroke initiated at ground level according to the classical TL model is expressed through a factor equal to $\mathrm{k}_{\text {tall }}=\left[1+(\mathrm{c} / \mathrm{v})\left(1-2 \rho_{\mathrm{t}}\right)\right] /\left(1-\rho_{\mathrm{t}}\right)$, where $\mathrm{V}$ and $\mathrm{C}$ are the return stroke front speed and the speed of light in vacuum, respectively, and $\rho_{\mathrm{t}}$ is the top reflection coefficient. Since the top reflection coefficient $\rho_{\mathrm{t}}$ is typically negative, lightning strikes to tall towers can result in a significant enhancement of the radiated electromagnetic field, which can be a few times larger than the field radiated by a similar return stroke but initiated at ground level. For very short towers and/or very slow return stroke current wavefronts, when condition $t_{f} \gg h / c$ applies, expressions relating the far electromagnetic field and the return stroke current were also derived. For the case of return strokes initiated at ground level $(h=0)$, the derived expressions represent a generalization of Eqs. (1) and (2), in which grounding conditions are taken into account. In this case, the field enhancement relative to a return stroke initiated at ground level (according to the classical TL model) is expressed through a factor equal to $\mathrm{k}_{\text {short }}=$ $\left(1+(\mathrm{c} / \mathrm{v}) \rho_{\mathrm{ch}-\mathrm{g}}\right) /\left(1+\rho_{\mathrm{ch}-\mathrm{g}}\right)$, where $\rho_{\mathrm{ch}-\mathrm{g}}$ represents the reflection coefficient between the lightning channel and the grounding impedance.

The presented results are based on the TL model for the return stroke. However, in a recent study [22], Pavanello et al. have shown that the early-time response of the electromagnetic fields radiated by lightning strikes to elevated strike objects is nearly independent of the return stroke model. Therefore, the derived expressions for towerinitiated strikes can also be considered as applicable for other engineering models.

\section{Acknowledgments}

This work was funded by the Swiss National Science Foundation (Grant No. 2000-068147) and 200020-109495. The authors express their gratitude to Prof. Carlo Alberto Nucci for his valuable comments on the manuscript.

\section{References}

[1] K.L. Cummins, E.P. Krider, M.D. Malone, The US National Lightning Detection Network (TM) and applications of cloud-toground lightning data by electric power utilities, IEEE Trans. Electromag. Compat. 40 (1998) 465-480.

[2] N. Herodotou, W.A. Chisholm, W. Janischewskyj, Distribution of lightning peak stroke currents in Ontario using an LLP system, IEEE Trans. Power Deliver. 8 (1993) 1331-1339.

[3] V.A. Rakov, R. Thottappillil, M.A. Uman, On the empirical formula of Willett et al. relating lightning return-stroke peak current and peak electric field, J. Geophys. Res. 97 (1992) 11527-11533.

[4] R. Thottappillil, M.A. Uman, Comparison of lightning return-stroke models, J. Geophys. Res. 98 (1993) 22903-22914.

[5] W. Janischewskyj, V. Shostak, J. Barratt, A.M. Hussein, I. Rusan, J.S. Chang, Collection and use of lightning return stroke parameters taking into account characteristics of the struck object, in: presented at 23rd ICLP (International Conference on Lightning Protection), Florence, Italy, 1996.

[6] F. Rachidi, W. Janischewskyj, A.M. Hussein, C.A. Nucci, S. Guerrieri, B. Kordi, J.S. Chang, Current and electromagnetic field associated with lightning return strokes to tall towers, IEEE Trans. Electromag. Compat. 43 (2001) 356-366.

[7] W. Janischewskyj, A.M. Hussein, V. Shostak, P. Dzurevych, W.A. Chisholm, Analysis of electromagnetic fields from lightning strikes to the Toronto $\mathrm{CN}$ tower and from lightning in the surrounding area, in: presented at CIGRE Symposium on Power System Electromagnetic Compatibility, Lausanne, Switzerland, 1993.

[8] O. Beierl, Front shape parameters of negative subsequent strokes measured at the Peissenberg tower, in: presented at 21st ICLP (International Conference on Lightning Protection), Berlin, Germany, 1992.

[9] F. Rachidi, M. Ianoz, C. A. Nucci, C. Mazzetti, Modified transmission line model for LEMP calculations. Effect of the return stroke velocity decreasing and elevated strike objects on close fields, in: presented at ninth International Conference on Atmospheric Electricity, St. Petersburg, Russia, 1992.

[10] J.C. Willett, V.P. Idone, R.E. Orville, C. Leteinturier, A. Eybert Berard, L. Barret, E.P. Krider, An experimental test of the 'transmission-line model' of electromagnetic radiation from triggered lightning return strokes, J. Geophys. Res. 93 (1988) 3867-3878.

[11] G. Diendorfer, Effect of an elevated strike object on the lightning electromagnetic fields, in: presented at Ninth International Symposium on Electromagnetic Compatibility, Zurich, Switzerland, 1991.

[12] S. Guerrieri, F. Heidler, C.A. Nucci, F. Rachidi, M. Rubinstein, Extension of two return stroke models to consider the influence of elevated strike objects on the lightning return stroke current and the radiated electromagnetic field: comparison with experimental results, in: presented at EMC '96 (International Symposium on Electromagnetic Compatibility), Rome, Italy, 1996. 
[13] R. Rusan, W. Janischewskyj, A.M. Hussein, J.S. Chang, Comparison of measured and computed electromagnetic fields radiated from lightning strikes to the Toronto $\mathrm{CN}$ tower, in: presented at 23rd ICLP (International Conference on Lightning Protection), Florence, Italy, 1996.

[14] W. Janischewskyj, V. Shostak, A.M. Hussein, Comparison of lightning electromagnetic field characteristics of first and subsequent return strokes to a tall tower 1. Magnetic field, in: presented at 24th ICLP (International Conference on Lightning Protection), Birmingham, UK, 1998.

[15] V. Shostak, W. Janischewskyj, A. Hussein, B. Kordi, Electromagnetic fields of lightning strikes to a tall tower: a model that accounts for upward-connecting discharges, in: presented at 25th ICLP (International Conference on Lightning Protection), Rhodes, Greece, 2000.

[16] F. Rachidi, V.A. Rakov, C.A. Nucci, J.L. Bermudez, The effect of vertically-extended strike object on the distribution of current along the lightning channel, J. Geophys. Res. 107 (2002) 4699.

[17] J.L. Bermudez, F. Rachidi, W. Janischewskyj, A.M. Hussein, M. Rubinstein, D. Pavanello, V. Shostak, M. Paolone, J.S. Chang, Influence of the height of an elevated strike object on the enhancement of lightning radiated fields, in: presented at 2003 IEEE Bologna PowerTech Conference, Bologna, Italy, 2003.

[18] M.A. Uman, D.K. McLain, E.P. Krider, The electromagnetic radiation from a finite antenna, Am J. Phys. 43 (1975) 33-38.

[19] J.L. Bermudez, F. Rachidi, W. Janischewskyj, V. Shostak, M. Rubinstein, D. Pavanello, A.M. Hussein, J.S. Chang, C.A. Nucci, M. Paolone, Far field - current relationship for lightning return strokes to elevated strike objects, IEEE Trans. Electromag. Compat., (2003) 20, submitted.

[20] V.A. Rakov, Transient response of a tall object to lightning, IEEE Trans. Electromag. Compat. 43 (2001) 654-661.

[21] H. Motoyama, W. Janischewskyj, A.M. Hussein, R. Rusan, W.A. Chisholm, J.S. Chang, Electromagnetic field radiation model for lightning strokes to tall structures, IEEE Trans. Power Deliver. 11 (1996) 1624-1632.

[22] D. Pavanello, F. Rachidi, V.A. Rakov, C.A. Nucci, J.L. Bermudez, Return stroke current profiles and electromagnetic fields associated with lightning strikes to tall towers: comparison of engineering models, J. Electrostat. 65 (2007) 316-321; this issue. 